\title{
АДАПТАЦІЯ УКРАЇНОМОВНОЇ ВЕРСIÏ «SPIRITUAL HEALTH ASESSMENT SCALE» (SHAS)
}

\author{
Лазорко Ольга \\ Волинський національний університет імені Лесі Українки, \\ м. Луцьк, Україна \\ lazorko.olha@vnu.edu.ua \\ ORCID ID: https://orcid.org/0000-0002-8427-5049
}

Мета. У статті представлені результати україномовної адаптації опитувальника «Шкала оцінки духовного здоров’я», розробленого в 2014 році Др. К. Л. Гаур (Індія), призначеного для вимірювання стану духовного здоров’я особистості. Шкала містить три субшкали для вимірювання духовного здоров’я: саморозвиток, самоактуалізація та самореалізація. Кожна субшкала містить сім тверджень, що стосуються означених понять. Основна мета цього дослідження - переклад, адаптація та стандартизація опитувальника для української вибірки.

Методи. Теоретичний аналіз дав змогу систематизувати сучасне розуміння духовності та духовного здоров’я особистості, а також проаналізувати складові компоненти цього конструкту в англомовній версії опитувальника, показники його надійності та валідності. Було розглянуто потенціал розвитку духовності під час одужання пацієнтів із різними видами фізичних та психічних розладів у клінічній практиці.

Емпіричний аналіз полягав у перевірці психометричних властивостей україномовної версії опитувальника. Для цього було проведено процедуру подвійного перекладу тексту та його експертної оцінки, перевірку валідності та надійності тесту відповідно до психометричних вимог, а також стандартизацію тесту на неклінічній вибірці.

Результати. Процедура адаптації опитувальника SHAS продемонструвала високі психометричні властивості: показники надійності та конструктної валідності цілком відповідають психометричним вимогам. Показник внутрішньої узгодженості (Коефіцієнт Кронбаха альфа) становить 0,79, показник ретестової надійності $-\mathrm{r}=0,76, \mathrm{p}<0,01$. Конструктна валідність оцінювалася шляхом кореляції субшкал методики зі шкалами інших психодіагностичних методик та продемонструвала задовільні показники значущості за більшістю показників. Отже, «Шкала оцінки духовного здоров’я» може бути якісним інструментом вимірювання рівня духовного здоров'я особистості.

Висновки. Створення україномовної адаптації психодіагностичної

ISSN 2308-3743 (Online), ISSN 2227-1376 (Print)

(C) Лазорко О., 2021. Ця стаття відкритого доступу на умовах CC BY-NC 4.0 
методики «Шкала оцінки духовного здоров'я» дає змогу зробити висновки про можливість та доцільність подальшого використання україномовної версії опитувальника як психодіагностичного інструменту для визначення об'єктивного рівня розвитку духовного здоров'я особистості. Цей інструмент привабливий для психотерапевтичної практики, адже містить відносно небагато тверджень і водночас описує найважливіші компоненти духовного здоров'я особистості. Шкалу можна використовувати для визначення прогресу клієнта в терапіях різних напрямів. У перспективі наукових пошуків - адаптація та можлива специфікація опитувальника для вузьких груп населення, зокрема тих, які мають психічні розлади на клінічній вибірці.

Ключові слова: духовність, духовне здоров'я, саморозвиток, самоактуалізація, самореалізація.

\section{Lazorko Olha. Adaptation of the Ukrainian version of the «Spiritual Health Assessment Scale» (SHAS).}

Purpose. The article presents the results of the Ukrainian-language adaptation of the questionnaire «Personal Spiritual Health Assessment Scale», developed in 2014 by K.L. Gaur (Republic of India), designed to measure the state of mental health of the individual. The scale contains three blocks for measuring spiritual health: Self-development, Self-actualization, and Self-realization. Each block contains seven statements relating to these concepts. The primary purpose of this study is the translation, adaptation and standardization of this questionnaire for the Ukrainian sample.

Methods. The theoretical analysis made it possible to systematize the modern understanding of spirituality and spiritual health of the individual and analyze the components of this construct in the English version of the questionnaire, indicators of its reliability and validity. The potential for the development of spirituality in the recovery process of patients with various types of physical and mental disorders in clinical practice was considered.

The empirical analysis consisted of testing the psychometric properties of the Ukrainian version of the questionnaire. To do this, we performed a procedure of double translation of the text and their expert evaluation, verification of the validity and reliability of the test under psychometric requirements, and standardization of the test on a non-clinical sample.

Statistical data processing was performed using factor analysis.

Results. The procedure of adaptation of the SHAS questionnaire demonstrated high psychometric properties: indicators of reliability and design validity fully meet the psychometric requirements. The internal consistency index (Cronbach's alpha) is 0.79 , the retest reliability index is $\mathrm{r}=0.76, \mathrm{p}<0.01$. Constructive validity was assessed by correlating the subscales of the method with the scales of other psychodiagnostic methods and demonstrated satisfactory significance indicators for most indicators. Thus, the «Spiritual Health Assessment Scale» can be considered a quality tool for measuring a person's spiritual health.

Conclusions. Based on the results of the adaptation process of the 
psychodiagnostic method «Spiritual Health Assessment Scale», it is possible to conclude the possibility and expediency of further use of the Ukrainian version of the questionnaire as a psychodiagnostic tool to determine the objective level of mental health. This tool is attractive for psychotherapy because it contains few statements but describes the essential components of a person's spiritual health. The scale can determine the client's progress in the treatment of various areas. Prospects for further research are the adaptation and possible specification of the questionnaire for narrow groups of the population, particularly those with mental disorders, in the clinical sample.

Keywords: spirituality, spiritual health, self-development, self-actualization, self-realization.

\section{Лазорко Ольга. Адаптация украиноязычной версии «Spiritual Health} Assessment Scale» (SHAS).

Цель. В статье представлены результаты украиноязычной адаптации опросника «Шкала оценки духовного здоровья личности», разработанного в 2014 году К. Л. Гаур (Республика Индия), предназначенного для измерения состояния духовного здоровья личности. Шкала содержит три блока для измерения духовного здоровья: саморазвитие, самоактуализация и самореализация. Каждый блок содержит семь утверждений, относящихся к указанным понятиям. Основная цель данного исследования - перевод, адаптация и стандартизация опросника для украинской выборки.

Методы. Теоретический анализ позволил систематизировать современное понимание духовности и духовного здоровья личности, а также проанализировать составляющие компоненты данного конструкта в англоязычной версии опросника, показатели его надежности и валидности. Был рассмотрен потенциал развития духовности в процессе выздоровления пациентов с разными видами физических и психических расстройств в клинической практике.

Эмпирический анализ заключался в проверке психометрических свойств украиноязычной версии опросника. Для этого была осуществлена процедура двойного перевода текста и его экспертной оценки, проверка валидности и надежности теста в соответствии с психометрическими требованиями, а также стандартизация теста на неклинической выборке. Статистическая обработка данных производилась с помощью факторного анализа.

Результаты. Проведенная процедура адаптации опросника SHAS продемонстрировала высокие психометрические свойства: показатели надежности и конструктной валидности полностью отвечают психометрическим требованиям. Показатель внутренней согласованности (коэффициент Кронбаха альфа) составляет 0,79, показатель ретестовой надежности $\mathrm{r}=0,76, \mathrm{p}<0,01$. Конструктная валидность оценивалась путем корреляции субшкал методики со шкалами других психодиагностических методик и продемонстрировала удовлетворительные показатели значимости по большинству показателей. Следовательно, «Шкала оценки духовного здоровья» 
может быть качественным инструментом измерения уровня духовного здоровья личности.

Выводы. По результатам адаптации психодиагностической методики «Шкала оценки духовного здоровья» можно сделать выводы о возможности и целесообразности дальнейшего использования украиноязычной версии опросника как психодиагностического инструмента для определения объективного уровня развития духовного здоровья личности. Этот инструмент привлекателен для психотерапевтической практики, поскольку содержит относительно немного утверждений, но описывает важнейшие компоненты духовного здоровья личности. Шкалу можно использовать для определения прогресса клиента в терапии разных направлений. Перспективами дальнейших научных изысканий является адаптация и возможная спецификация опросника для узких групп населения, в частности, имеющих психические расстройства на клинической выборке.

Ключевые слова: духовность, духовное здоровье, саморазвитие, самоактуализация, самореализация.

Вступ. Якщо на початку XX століття психологія та психотерапія заперечували роль духовності як синоніму релігії в лікуванні пацієнтів та надавала перевагу тілесному аспекту лікування розладів (Лазорко, 2018), то з появою гуманістичної течії в психології біопсихосоціальна модель як концепція єдності душі та тіла стала фундаментальною для розуміння цілісності людини. Врахування соціокультурних факторів впливу на здоров'я особистості в контексті єдності фізичного, психічного та духовного здоров'я має великий потенціал у практиці консультативної та психотерапевтичної діяльності. Духовність походить від латинського слова «spiritus», що означає нематеріальну життєву силу всередині тіла. Духовні пошуки включають пошук екзистенційного сенсу, в контексті чітко визначеної релігійної традиції чи без неї. Це прагнення може містити або не містити надприродний компонент; воно було визначено як способи, за допомогою яких люди розуміють i шукають трансцендентний сенс i цінність (Kliewer, Saultz, 2006). Ми концептуалізуємо фізичний, психічний та духовний виміри здоров'я як частину однієї системи. Ці параметри можуть мати свій унікальний внесок у загальне здоров'я людини, але їх не можна розглядати окремо одне від одного. Отже, ми пропонуємо цілісну модель здоров'я (Рис.1), яка передбачає взаємний зв'язок між фізичним, психічним i духовним вимірами здоров'я, які вбудовані в специфічний соціокультурний контекст. 


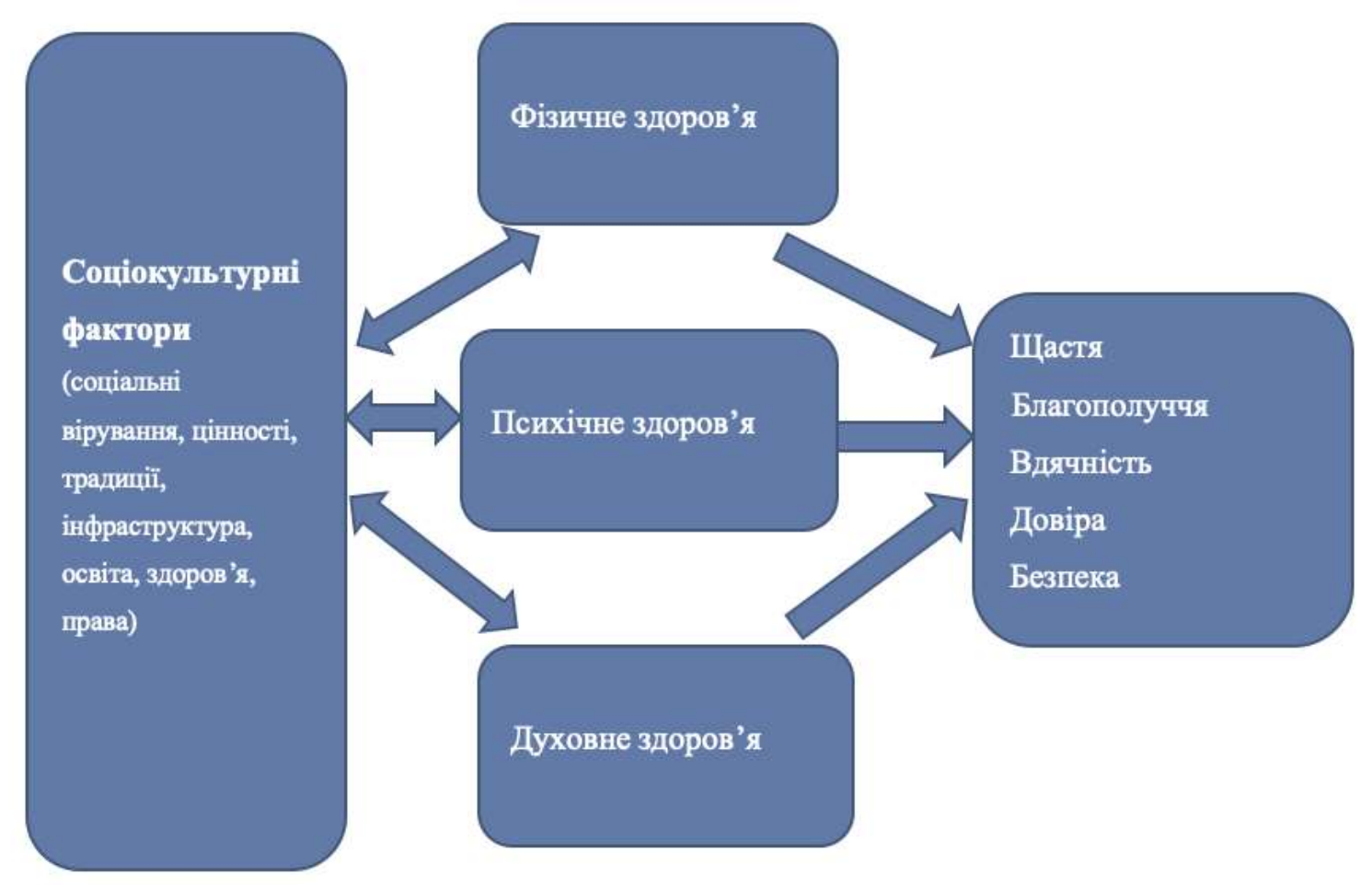

\section{Рис.1. Холістична модель здоров'я особистості в соціокультурному контексті}

Схема демонструє взаємозв'язок трьох компонентів здоров'я фізичного, психічного та духовного, загального здоров'я та щастя людини, а також вказує важливість соціального контексту та культурних факторів, які визначають зв'язок цих трьох компонентів здоров'я з благополуччям людини.

На сьогодні практично відсутні україномовні об'єктивні психодіагностичні методики для вимірювання рівня духовного здоров'я особистості як невід'ємного елемента загального здоров'я особистості.

Духовність двадцять першого століття $є$ постмодерністською і феноменологічною за своєю природою тому, що вона захищає та схвалює пережитий індивідами досвід (Hage, 2006). На відміну від традиційної духовності, яка підкреслювала ієрархічні структури влади з винятковими рецептами духовного зростання і сповідувала лише одну «Істину» (Fukuyama, Sevig, 2002), постмодерністська перспектива визнає зміни і не змагається за одну абсолютну версію реальності чи абсолютну «Істину», а скоріше підкреслює роль індивіда в побудові власних «істин» для встановлення світогляду. Духовність двадцять першого століття грунтується на демократичному та різноманітному погляді на духовні традиції та 
історію і відходить від релігійного дискурсу. Якщо релігійна приналежність $є$ вибором людини, то духовність - фундаментальний вимір людської сутності, значна частина життя, яка дає змогу розуміти себе за межами рівня Его (Corrigan, McCorkle, Schell, \& Kidder, 2003). Духовність відрізняється від релігії, оскільки остання пов'язана скоріше зі специфічними ритуалами, інституційними залежностями та соціальними стосунками, тоді як перша більше стосується особистого досвіду того, що є невидимим і визнаним більшим, ніж ми самі (Swinton, 2001). Якщо одні науковці розглядають духовність як один із вимірів особистості (Kliewer \& Saultz, 2006), то інші - як основний компонент та точку перетину між усіма особистісними вимірами (Колісник, 2011; Pargament, 2007). Сучасні наукові дослідження підкреслюють важливу роль духовності в роботі з пацієнтами з різними захворюваннями (Kearney \& Mount, 2000; Lukoff, 2007; Puchalski, 2012). Використання духовних практик у консультуванні та психотерапії сьогодні - надзвичайно актуальне (Hathaway, 2008; Plante, 2009; Saunders, Miller \& Bright, 2010).

Крізь призму функціонального підходу духовне здоров'я можна охарактеризувати ієрархічною домінантністю розвинених психічних функцій людини, до яких Л.С. Виготський відносив свідомість, самосвідомість та волю.

Духовне здоров'я - важливий компонент благополуччя та ключовий елемент холістичного підходу до здоров'я. Фізичне, психічне та духовне здоров’я глибоко переплетені між собою і чинять вплив одне на одного. Щоби бути здоровим, потрібно мати духовне життя; людина має мати певні цінності та переконання, якими живе i яких прагне досягти. Ці цінності мають бути інтегровані в професійне, особисте та соціальне життя. «Духовне життя» передусім відображається у стосунках із самим собою, сім'єю та світом загалом. Отож, високий рівень духовного здоров'я особистості пов'язується 3 саморозвитком, самоактуалізацією та самореалізацією особистості та $\epsilon$ трансцендентальним виходом за межі або вищим проявом «справжнього Я».

Аналіз наявних психодіагностичних інструментів вимірювання рівня духовного здоров'я засвідчив, що більшість із них не може застосовуватися в позарелігійному дискурсі, оскільки містить велику кількість тверджень стосовно віри в Бога чи релігії (Ellison, 2002; Gomez, Fisher, 2005). Інші шкали, що вимірюють духовне здоров'я, 
зосереджуються на впливі духовності індивіда на розвиток організації, а не на особистісному зростанні (наприклад, Rojas, 2002). На відміну від вище описаних методик, «Шкала оцінки духовного здоров'я» (SHAS) має три субшкали для вимірювання рівня духовного здоров'я (саморозвиток, самоактуалізація та самореалізація), дає можливість об'єктивно визначити рівень духовного здоров'я особистості та позбавлена релігійних чи культурних упереджень, оскільки грунтується на власному духовному досвіді.

Мета цього дослідження - переклад, адаптація та стандартизація опитувальника «Personal Spiritual Health Assessment Scale» (SHAS) для української вибірки. Важливим завданням дослідження бачиться концептуалізація понять «духовність», «духовне здоров'я» та 3'ясування їх місця в структурі загального здоров'я особистості.

Методи та процедура дослідження. «Шкалу оцінки духовного здоров'я», яку призначено для вимірювання стану духовного здоров'я особистості, розробили індійські фахівці Др. К. Л. Гаур та М. Шарма (Gaur, Sharma, 2014). Шкала містить три субшкали для вимірювання духовного здоров'я: саморозвиток, самоактуалізація та самореалізація. Кожна субшкала містить сім тверджень, що стосуються означених понять. Кожне твердження оцінюється за шкалою Лайкерта від 1 до 5 залежно від сили його прояву в досліджуваного. В такий спосіб кожен блок може бути оцінений сукупно від 7 до 25 балів, а загальний показник духовного здоров’я від 21 до 105 балів.

Тож цей опитувальник - короткий та зручний у використанні інструмент для оцінки загального рівня духовного здоров'я. Результати авторської стандартизації свідчать про високу надійність та конструктну валідність, які було перевірено на вибірці з 1050 осіб віком 20-60 років. Оригінальна версія опитувальника продемонструвала високі показники ретестової надійності $(81,14 \%)$. Достовірність внутрішньої консистенції оцінено за допомогою коефіцієнту Кронбаха альфа $(0,82)$.

Обговорення результатів. Вибірка для проведення адаптації «Шкали оцінки духовного здоров'я» складалася 3110 респондентів, 3 них 89 - жіночої і 21 чоловічої статі. Вік опитуваних становив від 18 до 64 років. Опитування для дослідження проводилося за допомогою застосування онлайн-форми опитування на платформі Google Forms. 
На першому етапі дослідження було здійснено лінгвістичну адаптацію шкали оцінки рівня духовного здоров'я, яка полягала в перекладі $з$ англійської на українську мову зі збереженням смислових концептів. Перекладали два незалежні лінгвісти: прямий і зворотний варіанти. Після цього обидва англомовні варіанти пройшли процедуру експертної оцінки психолога, який вільно володіє англійською та українською мовами - для корекції точності та відповідності оригіналу. Наступним кроком була перевірка внутрішньої консистентності та ретестової надійності субшкал (див. табл. 1). Перший показник було визначено на вибірці зі 110 осіб, інший - на вибірці 77 осіб зі збереженням вікової та статевої репрезентації, опитаних з інтервалом в 4 тижні.

Таблиця 1

Перевірка внутрішньої консистентності шкал україномовної

\section{версії «Шкали оцінки духовного здоров'я»}

\begin{tabular}{|l|c|c|c|}
\hline \multicolumn{1}{|c|}{ Назва шкали } & $\begin{array}{c}\text { Середнє } \\
\text { значення }\end{array}$ & $\begin{array}{c}\text { Стандартне } \\
\text { відхилення }\end{array}$ & $\begin{array}{c}\text { Коефіцієнт } \boldsymbol{\alpha} \\
\text { Кронбаха }\end{array}$ \\
\hline Саморозвиток & 28 & 0,511 & 0,813 \\
\hline Самоактуалізація & 21 & 0,596 & 0,758 \\
\hline Самореалізація & 24 & 0,658 & 0,811 \\
\hline
\end{tabular}

Отримані значення коефіцієнту альфа Кронбаха (середнє значення - 0,79) досить високі та свідчать про внутрішню надійність всіх трьох шкал методики. Вони співвідносні 3 показником оригінальної методики $(0,82)$.

Отриманий показник ретестової кореляції (середнє значення 0,76) становить $\mathrm{r}=0,72$ (шкала саморозвитку); $\mathrm{r}=0,76$ (шкала самоактуалізації); $\mathrm{r}=0,79$ (шкала самореалізації), $\mathrm{p}<0,01$, що $\epsilon$ задовільним показником ретестової надійності україномовної версії Шкали. Отже, перевірка ретестової надійності свідчить про високу стійкість діагностованих показників.

Субшкали «Шкали оцінки духовного здоров'я» представлені 21 твердженням (по 7 до кожної шкали):

\section{Саморозвиток:}

1. Розважливість, тобто мудрість у прийнятті рішень

2. Вдячність, тобто повага до інших

3. Великодушність, тобто відчуття рівності

4. Благодійність, тобто допомога людям

5. Терпіння, тобто спокій у негативних станах

6. Самоконтроль, тобто здатність контролювати емоції 
7. Моральні дії, тобто дії відповідно до власних моральних цінностей

\section{Самореалізація:}

1. Самоаналіз: як багато ви думали про себе.

2. Мета життя: як багато ви знаєте про мету свого життя.

3. Життєвий шлях: наскільки ви знаєте про те, як ви хочете прожити своє життя.

4. Сильні сторони: як багато ви знаєте про власні сильні сторони.

5. Слабкі сторони: як багато ви знаєте про власні слабкості.

6. Опанування: наскільки вправно ви можете впоратися зі своїми слабкостями.

7. Кінець життя: наскільки багато ви думали про кінець свого життя.

\section{Самореалізація:}

1. Відсутність тривожних думок: врівноважений стан душі.

2. Холізм: відчувати себе єдиним цілим.

3. Задоволення: відчуття самозадоволеності, тобто повноти.

4. Свобода: відчуття повної свободи.

5. Мудрість: розуміння вічних цінностей.

6. Блаженство: відчуття насолоди всередині себе.

7. «Шосте чуття»: інтуїція, натхнення від свого внутрішнього «Я».

Кожен із пунктів оцінюється за 5-бальною шкалою Лайкерта, тобто оцінка «1» за «Ніколи», оцінка «2» за «Рідко», оцінка «3» за «Рідко», оцінка «4» за «Часто» та оцінка «5» для «Завжди»

Отож, кожна оцінка субшкали коливається від «7» до «35», а загальний показник духовного здоров’я - від «21» до «105».

Нормативні показники україномовної версії Шкали співвідносні 3 оригінальною методикою (табл. 2) та дають змогу визначити три рівні духовного здоров’я: низький рівень від «21» до «49», середній рівень від «49» до «77» і високий рівень від «77» до «105» балів.

Таблиия 2

Нормативні показники україномовної версії «Шкали оцінки духовного здоров'я»

\begin{tabular}{|l|c|c|c|}
\hline & Загальна вибірка & Чоловіки & Жінки \\
\hline Середнє значення (M) & 65,54 & 61,18 & 67,23 \\
\hline Стандартне відхилення (SD) & 8,78 & 7,12 & 8,92 \\
\hline
\end{tabular}

Перевірка конструктної валідності блоків грунтувалася на структурних компонентах духовного здоров'я особистості, яке 
пов’язане 3 локусом контролю, цілями життя, автономією, особистісним зростанням, самосприйняттям, самоповагою, цілісністю, сприйняттям інших, гнучкістю поведінки та самоактуалізацією. Для валідизації використовувалися такі методики: «Тест смисложиттєвих орієнтацій» (Д. Лєонтьєв); «Опитувальник особистісної орієнтації» (Е. Шостром), які містять дотичні до субшкал оцінки духовного здоров’я шкали. Результати кореляційного аналізу представлені в таблиці 3.

Таблиия 3

\section{Результати кореляційного аналізу показників шкал методики «Шкала оцінки духовного здоров'я» та інших особистісних}

\section{характеристик.}

\begin{tabular}{|l|c|c|c|}
\hline \multicolumn{1}{|c|}{$\begin{array}{c}\text { Особистісні } \\
\text { характеристики }\end{array}$} & $\begin{array}{l}\text { Шкала } \\
\text { «Саморозвиток» }\end{array}$ & $\begin{array}{l}\text { Шкала } \\
\text { «Самоактуалізація» }\end{array}$ & $\begin{array}{l}\text { Шкала } \\
\text { «Самореалізація» }\end{array}$ \\
\hline Цілі в житті & $0,522^{* *}$ & 0,243 & $0,487^{* *}$ \\
\hline Локус контролю-Я & $0,431^{* *}$ & $0,432^{* *}$ & $0,420^{* *}$ \\
\hline Автономія & $0,327^{*}$ & $0,322^{*}$ & $0,456^{* *}$ \\
\hline $\begin{array}{l}\text { Особистісне } \\
\text { зростання }\end{array}$ & $0,550^{* *}$ & $0,321^{*}$ & $0,492^{* *}$ \\
\hline Самоприйняття (Sa) & $0,561^{* *}$ & $0,483^{* *}$ & $0,401^{* *}$ \\
\hline Самоповага (Sr) & $0,327^{*}$ & $0,311^{*}$ & $0,319^{*}$ \\
\hline Синергія (Sy) & $0,325^{*}$ & $0,327^{*}$ & 0,100 \\
\hline $\begin{array}{l}\text { Конструктивна } \\
\text { природа людини (Nc) }\end{array}$ & 0,127 & $0,594^{* *}$ & $0,403^{* *}$ \\
\hline Екзистенційність (Ex) & $0,486^{* *}$ & $0,559^{* *}$ & $0,420^{* *}$ \\
\hline $\begin{array}{l}\text { Цінність } \\
\text { самоактуалізаціі (Sav) }\end{array}$ & $0,319^{*}$ & $0,464^{* *}$ & $0,439^{* *}$ \\
\hline
\end{tabular}

* - кореляція $\epsilon$ значущою на рівні 0,05 ; ** - кореляція $є$ значущою на рівні 0,01

Отримані дані свідчать про достатній загальний рівень конкурентної валідності.

Серед обмежень методики можна виділити те, що адаптація проведена на неклінічній вибірці, що не дає змоги повною мірою оцінити духовне здоров'я людей 3 фізичними та психічними розладами.

Висновки і перспективи досліджень. Отже, духовність двадцять першого століття грунтується на демократичному та різноманітному погляді на духовні традиції та історію і відходить від релігійного дискурсу. Духовне здоров'я - важливий компонент благополуччя та ключовий елемент холістичного підходу до здоров'я. Фізичне, психічне та духовне здоров'я глибоко переплетені між собою i 
впливають одне на одного. Високий рівень духовного здоров'я особистості пов'язується із саморозвитком, самоактуалізацією та самореалізацією особистості та $є$ трансцендентальним виходом за межі або вищим проявом «справжнього Я».

За результатами проведеного процесу адаптації «Шкали оцінки духовного здоров'я» (ШОДЗ) можна зробити висновки про можливість та доцільність подальшого використання україномовної версії опитувальника як психодіагностичного інструменту для визначення об'єктивного рівня розвитку духовного здоров'я особистості. Загалом, адаптована україномовна версія методики ШОДЗ має задовільні показниками надійності й валідності, і може вважатися якісним інструментом вимірювання рівня духовного здоров'я особистості.

Цей інструмент привабливий для психотерапевтичної практики, адже містить відносно небагато тверджень i водночас описує найважливіші компоненти духовного здоров'я особистості. Шкалу можна використовувати для визначення прогресу клієнта в терапії різних напрямів.

Перспективами подальших наукових пошуків $\epsilon$ адаптація та можлива специфікація опитувальника для вузьких груп населення, зокрема для тих, які мають психічні розлади (на клінічній вибірці).

\section{Лiтература}

1. Corrigan, P., McCorkle, B., Schell, B., \& Kidder, K. (2003). Religion and spirituality in the lives of people with serious mental illness. Community Mental Health Journal, 39(6), 487-499.

2. Ellison Spiritual Well-Being Scale (SWBS). (2002). Available from: https://www.lifeadvance.com/spiritual-well-being-scale.html

3. Fukuyama, M. A., \& Sevig, T. D. (2002). Spirituality in counseling across cultures. In P. B. Pedersen, J. G. Draguns, W. R. Lonner \& J. E. Trimble (Eds.), Counseling across cultures (pp. 273-295). Thousand Oaks, CA: Sage.

4. Gaur, K. Gaur. (2014). Measuring Spiritual Health: Spiritual Health assessment Scale (SHAS). IJIRD, 63-67.

5. Gomez R, Fisher JW. (2005). The spiritual well-being questionnaire: Testing for model applicability, measurement and structural equivalencies, and latent mean differences across gender. Personality and Individual Differences, 39:1383-1393. DOI: https://doi.org/10.1016/j.paid.2005.03.023

6. Hage, S. M. (2006). A closer look at the role of spirituality in psychology training programs. Professional Psychology: Research and Practice, 37, 303-310. DOI: https://doi.org/10.1037/0735- 7028.37.3.303 
7. Hathaway, W. L. (2008). Clinical practice with religious/spiritual issues: Niche, proficiency or specialty? Journal of Psychology and Theology, 36, 16-25.

8. Kearney, M., \& Mount, B. (2000). Spiritual care of the dying patient. In $H$. M. Chochinov \& W. Breitbart (Eds.) Handbook of psychiatry in palliative medicine (pp. 357-373). Oxford, UK: Oxford University Press.

9. Kliewer, S. P., \& Saultz, J. (2006). Healthcare and spirituality. Oxford: Radcliffe Publishing.

10. Lukoff, D. (2007). Spirituality in the recovery from persistent mental disorders. Southern Medical Journal, 100, 642- 646. DOI: https://doi.org/10.1097/SMJ .0b013e3180600ce2

11. Pargament, K. I. (2007). Spiritually integrated psychotherapy: Understanding and addressing the sacred. New York, NY: Guilford Press.

12. Plante, T. G. (2009). Spiritual practices in psychotherapy: Thirteen tools for enhancing psychological health. Washington, DC: American Psychological Association. DOI: https://doi.org/10.1037/11872-000

13. Puchalski, C. M. (2012). Spirituality in the cancer trajectory. Annals of oncology, 23(3), 49-55.

14. Rojas Raymond Ronald (2002). Management Theory and Spirituality: A framework and Validation of the Independent Spirituality Assessment Scale. A Dissertation presented to the Faculty of Argosy University in partial fulfillment of the requirements for the degree of Doctor of Business Administration. Available from http://www.prismleadership.com/d.pdf.

15. Saunders, S. M., Miller, M. L., \& Bright, M. M. (2010). Spiritually conscious psychological care. Professional Psychology: Research and Practice, 41(5), 355-362. DOI: https://doi.org/10.1037/a0020953

16. Swinton, J (2001). Spirituality and Mental Health Care: Rediscovering a 'Forgotten' Dimension. J. Kingsley Publishers, London, Philadelphia.

17. Колісник, О. П. (2011). Духовний саморозвиток і духовне здоров'я особистості. Соціальна психологія, 4, 52-63.

18. Лазорко О.В. (2018). Сучасні перспективи використання духовних практик у роботі клінічного психолога. Психологічні перспективи, (32), 172181. https://doi.org/10.29038/2227-1376-2018-32-172-181

\section{References}

1. Corrigan, P., McCorkle, B., Schell, B., \& Kidder, K. (2003). Religion and spirituality in the lives of people with serious mental illness. Community Mental Health Journal, 39(6), 487-499.

2. Ellison Spiritual Well-Being Scale (SWBS). (2002). Available from: https://www.lifeadvance.com/spiritual-well-being-scale.html

3. Fukuyama, M. A., \& Sevig, T. D. (2002). Spirituality in counseling across cultures. In P. B. Pedersen, J. G. Draguns, W. R. Lonner \& J. E. Trimble (Eds.), Counseling across cultures (pp. 273-295). Thousand Oaks, CA: Sage.

4. Gaur, K. Gaur. (2014). Measuring Spiritual Health: Spiritual Health assessment Scale (SHAS). IJIRD. P 63-67. 
5. Gomez R, Fisher JW. (2005). The spiritual well-being questionnaire: Testing for model applicability, measurement and structural equivalencies, and latent mean differences across gender. Personality and Individual Differences, 39:1383-1393. DOI: https://doi.org/10.1016/j.paid.2005.03.023

6. Hage, S. M. (2006). A closer look at the role of spirituality in psychology training programs. Professional Psychology: Research and Practice, 37, 303-310. DOI: https://doi.org/10.1037/0735- 7028.37.3.303

7. Hathaway, W. L. (2008). Clinical practice with religious/spiritual issues: Niche, proficiency or specialty? Journal of Psychology and Theology, 36, 16-25.

8. Kearney, M., \& Mount, B. (2000). Spiritual care of the dying patient. In H. M. Chochinov \& W. Breitbart (Eds.) Handbook of psychiatry in palliative medicine (pp. 357-373). Oxford, UK: Oxford University Press.

9. Kliewer, S. P., \& Saultz, J. (2006). Healthcare and spirituality. Oxford: Radcliffe Publishing

10. Lukoff, D. (2007). Spirituality in the recovery from persistent mental disorders. Southern Medical Journal, 100, 642-646. DOI: https://doi.org/10.1097/SMJ .0b013e3180600ce2

11. Pargament, K. I. (2007). Spiritually integrated psychotherapy: Understanding and addressing the sacred. New York, NY: Guilford Press.

12. Plante, T. G. (2009). Spiritual practices in psychotherapy: Thirteen tools for enhancing psychological health. Washington, DC: American Psychological Association. DOI: https://doi.org/10.1037/11872-000

13. Puchalski, C. M. (2012). Spirituality in the cancer trajectory. Annals of oncology, 23(3), 49-55.

14. Rojas Raymond Ronald (2002). Management Theory and Spirituality: A framework and Validation of the Independent Spirituality Assessment Scale. A Dissertation presented to the Faculty of Argosy University in partial fulfillment of the requirements for the degree of Doctor of Business Administration. Available from http://www.prismleadership.com/d.pdf.

15. Saunders, S. M., Miller, M. L., \& Bright, M. M. (2010). Spiritually conscious psychological care. Professional Psychology: Research and Practice, 41(5), 355-362. https://doi.org/10.1037/a0020953

16. Swinton J (2001) Spirituality and Mental Health Care: Rediscovering a 'Forgotten' Dimension. J. Kingsley Publishers, London, Philadelphia.

17. Kolisnyk, O. P. (2011). Dukhovnyi samorozvytok i dukhovne zdorovia osobystosti [Spiritual self-development and spiritual health of the individual]. Sotsialna psykholohiia - Social Psychology, 4, 52-63. [in Ukrainian].

18. Lazorko, O. V. (2018). Suchasni perspektyvy vykorystannia dukhovnykh praktyk u roboti klinichnoho psykholoha [The Contemporary Perspectives on Using Spiritual Practices in the Clinical Psychologist 'Work]. Psykholohichni perspektyvy Psychological Prospects Journal, (32), 172-181. https://doi.org/10.29038/2227-13762018-32-172-181 [in Ukrainian]. 